\title{
Is It Time to Modify Definition of Occult Pneumothorax?
}

\author{
Sourav Burman ${ }^{1}$ Vineet Chowdhary ${ }^{1}$ Charu Mahajan ${ }^{1}$ Indu Kapoor ${ }^{1}$ Hemanshu Prabhakar ${ }^{1}$
}

${ }^{1}$ Department of Neuroanaesthesiology and Critical Care, All India Institute of Medical Sciences (AIIMS), New Delhi, India

J Neuroanaesthesiol Crit Care 2021;8:147-148.

In this era of advanced medical technology, diagnosis and management of pneumothorax is rapid and accurate. However, diagnostic dilemma arises when clinical picture does not correlate with normal appearing chest X-ray. We present such a case of an occult pneumothorax (OP) diagnosed timely by an ultrasound and addressed promptly. Consent for publication was obtained from the next of kin of the patient.

A 28-year-old male patient presented to the emergency department with history of head trauma after road traffic injury and Glasgow coma scale (GCS) score of $\mathrm{E}_{1} \mathrm{~V}_{1} \mathrm{M}_{2}$. Computed tomography (CT) scan of the head revealed multiple large contusions with subdural hemorrhage and midline shift. There was no other apparent injury present and all other scans were normal. After tracheal intubation and stabilization, the patient was taken up for decompressive craniectomy. The surgery proceeded uneventfully except for high peak pressures $\left(28 \mathrm{~cm} \mathrm{H}_{2} \mathrm{O}\right)$, throughout the surgery. Postoperatively, the patient was shifted to neurointensive care unit (NICU) for mechanical ventilation. In the NICU, patient started to develop further high peak pressures with desaturation episodes $\left(\mathrm{SpO}_{2}: 88-90 \%\right)$. Arterial blood gas sample revealed decreased arterial oxygenation $\left(\mathrm{PaO}_{2}: 64 \mathrm{~mm} \mathrm{Hg}\right)$ for which no apparent cause could be found. Lung air entry was equal bilaterally and chest X-ray was also normal (-Fig. 1). An urgent bedside lung ultrasonography (USG) showed absent lung sliding on the left side, positive barcode sign, and a lung point present anteriorly ( - Fig. 2 ). These findings did not corroborate with the chest X-ray findings. After confirmation of pneumothorax on USG by a radiologist, a left-sided chest drain was inserted. The patient's oxygenation improved and over the next few days, we were able to wean him gradually from the ventilator.

Supine chest X-ray is an insensitive imaging for detection of pneumothorax, and incidence of such occult pneumothorax is approximately $5 \%$ of all trauma registry patients. ${ }^{1}$ Occult pneumothorax was originally defined as a pneumothorax identified on thoracic or abdominal CT that was not seen on

\section{Published online}

September 23, 2019
DOI https://doi.org/

$10.1055 / \mathrm{s}-0039-1697545$

ISSN 2348-0548.
Address for correspondence Charu Mahajan, MD, DM, Department of Neuroanaesthesiology and Critical Care, Neurosciences Centre, All India Institute of Medical Sciences (AIIMS), New Delhi, 110029, India (e-mail: charushrikul@gmail.com).

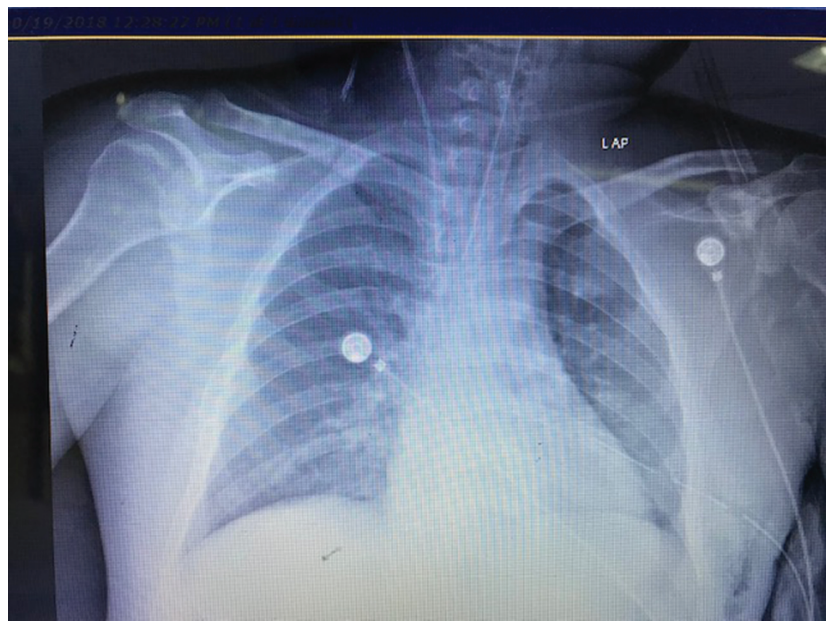

Fig. 1 Chest X-ray of the patient (anterior-posterior view).

conventional supine antero-superior chest radiography.,3 This patient may have developed occult pneumothorax after mechanical ventilation was started which explains the normal initial e-FAST (extended focused assessment with sonography in trauma) scan. We could not perform CT scan chest to rule out pneumothorax as the patient was unfit for transportation to radiological facility. The controversy of whether to treat it or not has been a question of contention and many advocate to manage OP conservatively with close monitoring. ${ }^{4}$ However, in our case, patient was on positive pressure ventilation, and had high airway pressures and compromised oxygenation. In view of all these factors, tube thoracostomy was performed and patient's oxygenation clinically improved.

The role of CT scan as a tool in identifying OP remains the gold standard. This case report adds to the vast literature which supports lung USG to be sensitive and as accurate as CT scan for diagnosis of occult pneumothorax when done in expert hands. ${ }^{5-7}$ Lichtenstein et al studied patients who underwent routine screening sonography for pneumothorax followed by CT scanning. They found that absence of
(C) 2019. Indian Society of Neuroanaesthesiology and Critical Care.

This is an open access article published by Thieme under the terms of the Creative Commons Attribution-NonDerivative-NonCommercial-License, permitting copying and reproduction so long as the original work is given appropriate credit. Contents may not be used for commercial purposes, or adapted, remixed, transformed or built upon. (https://creativecommons.org/licenses/by-nc-nd/4.0/).

Thieme Medical and Scientific Publishers Pvt. Ltd. A-12, 2nd Floor, Sector 2, Noida-201301 UP, India 


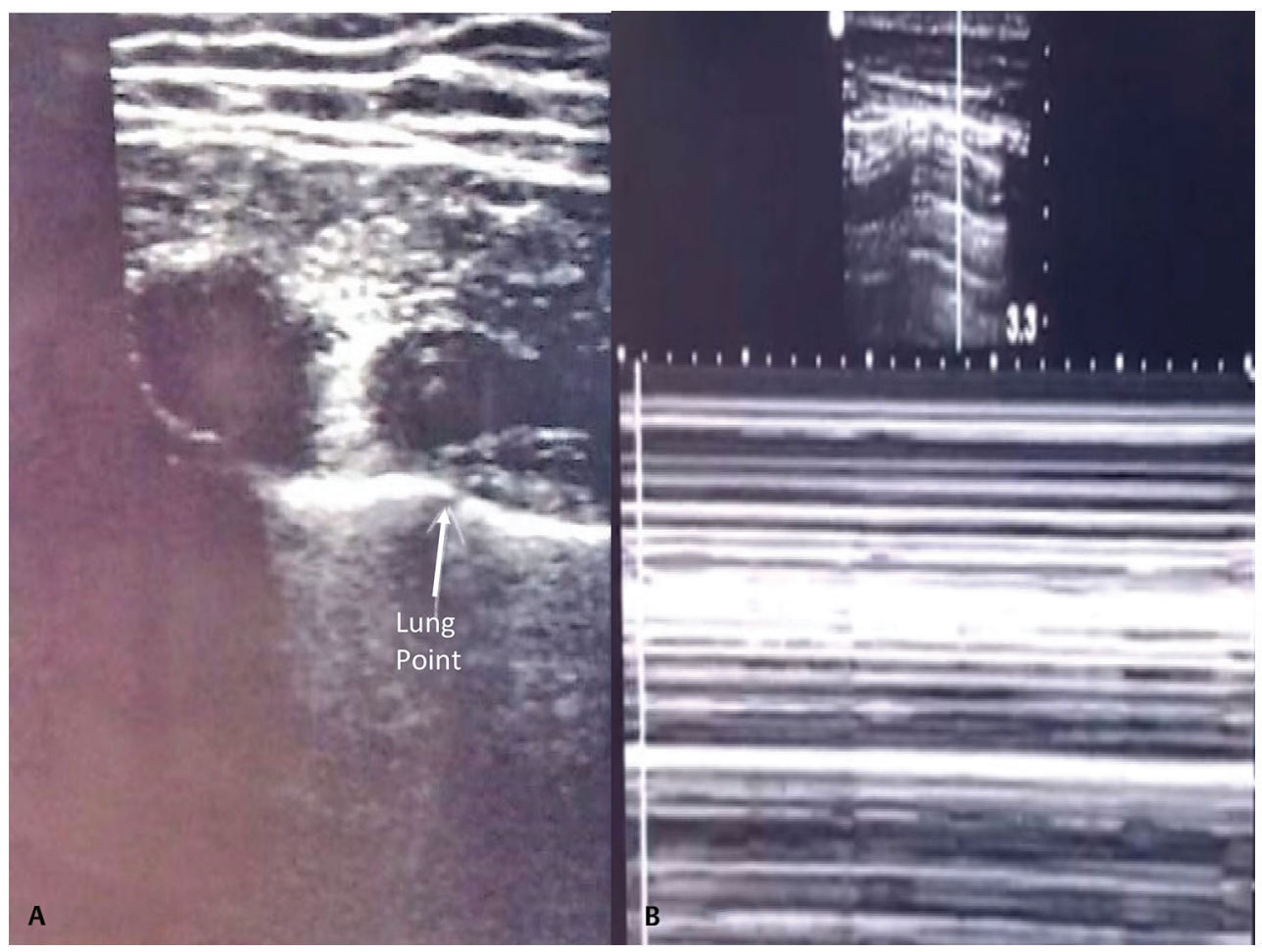

Fig. 2 Lung ultrasound showing (A) lung point in two-dimensional (2D) mode (B) barcode sign in the M-mode.

lung sliding on ultrasonography had a sensitivity of $100 \%$ and specificity of $78 \%$ for diagnosis of OP. Absence of lung sliding along with A-lines had a sensitivity of $95 \%$ and specificity of $94 \%$. The demonstration of lung point had a sensitivity of $79 \%$ and specificity of $100 \% .^{7}$ The authors suggest that in the absence of lung sliding, if lung point is not visualized, then only patient should be subjected to only radiography or CT scan. Thus, this decreases the need for CT. The advantages of USG as a tool for diagnosis of OP are high sensitivity, easy availability, high feasibility, simplicity, rapidness, cost-effectiveness, bedside monitoring with no involvement of radiations, and simple logistics.

More than two decades later, this definition of OP possibly needs consideration for revision. Lung USG has now become an integral part of critical care management and may be incorporated along with CT scan in definition of OP. Shall we redefine OP as "Pneumothorax not suspected in initial chest X-ray or clinical examination but detected on a CT scan or USG chest"?

\section{Funding}

None.

\section{Conflict of Interest}

None declared.

\section{References}

1 Ball CG, Kirkpatrick AW, Feliciano DV. The occult pneumothorax: what have we learned? Can J Surg 2009;52(5):E173-E179

2 Wall SD, Federle MP, Jeffrey RB, Brett CM. CT diagnosis of unsuspected pneumothorax after blunt abdominal trauma. AJR. Am J Roentgenol 1983;141(5):919-921

3 Tocino IM, Miller MH, Frederick PR, Bahr AL, Thomas F. CT detection of occult pneumothorax in head trauma. AJR. Am J Roentgenol 1984;143(5):987-990

4 Zhang M, Teo LT, Goh MH, Leow J, Go KT. Occult pneumothorax in blunt trauma: is there a need for tube thoracostomy? Eur J Trauma Emerg Surg 2016;42(6):785-790

5 Soldati G, Testa A, Sher S. Pignataro G, La Sala M, Silveri NG. Occult traumatic pneumothorax: diagnostic accuracy of lung ultrasonography in the emergency department. Chest 2008;133(1):204-211

6 Rowan KR, Kirkpatrick AW, Liu D, Forkheim KE, Mayo JR, Nicolaou S. Traumatic pneumothorax detection with thoracic US: correlation with chest radiography and CT-initial experience. Radiology 2002;225(1):210-214

7 Lichtenstein DA, Mezière G, Lascols $\mathrm{N}$, et al. Ultrasound diagnosis of occult pneumothorax. Crit Care Med 2005;33(6):1231-1238 